\title{
A Newly Created Meso-, Micro-, and Nano-Scale Rough Titanium Surface Promotes Bone-Implant Integration
}

\author{
Masakazu Hasegawa ${ }^{1,2}$, Juri Saruta ${ }^{1,3, *}$, Makoto Hirota ${ }^{1,4}{ }^{-}$, Takashi Taniyama ${ }^{1,5}$, \\ Yoshihiko Sugita ${ }^{2}$, Katsutoshi Kubo ${ }^{2}$, Manabu Ishijima ${ }^{1}$, Takayuki Ikeda ${ }^{1}$, Hatsuhiko Maeda ${ }^{2}$ \\ and Takahiro Ogawa ${ }^{1}$ \\ 1 Weintraub Center for Reconstructive Biotechnology, Division of Advanced Prosthodontics, UCLA School of \\ Dentistry, Los Angeles, CA 90095-1668, USA; masa.hasegawa0202@gmail.com (M.H); \\ mhirota@yokohama-cu.ac.jp (M.H.); taniyama.orth@tmd.ac.jp (T.T); manab612@gmail.com (M.I.); \\ ikeda.takayuki@nihon-u.ac.jp (T.I.); togawa@dentistry.ucla.edu (T.O) \\ 2 Department of Oral Pathology, School of Dentistry, Aichi Gakuin University, 1-100 Kusumoto-cho, \\ Chikusa-ku, Nagoya, Aichi 464-8650, Japan; yosshii@dpc.agu.ac.jp (Y.S); bobo@dpc.agu.ac.jp (K.K); \\ hatsu@dpc.aichi-gakuin.ac.jp (H.M) \\ 3 Department of Oral Science, Graduate School of Dentistry, Kanagawa Dental University, 82 Inaoka, \\ Yokosuka, Kanagawa 238-8580, Japan \\ 4 Department of Oral and Maxillofacial Surgery/Orthodontics, Yokohama City University Medical Center, \\ 4-57 Urafune-cho, Yokohama, Kanagawa 232-0024, Japan \\ 5 Department of Orthopedic Surgery, Yokohama City Minato Red Cross Hospital, 3-12-1 Shinyamashita, \\ Yokohama, Kanagawa 231-8682, Japan \\ * Correspondence: saruta@kdu.ac.jp; Tel./Fax: +81-46-822-9537
}

Received: 10 December 2019; Accepted: 23 January 2020; Published: 25 January 2020

Abstract: Titanium implants are the standard therapeutic option when restoring missing teeth and reconstructing fractured and/or diseased bone. However, in the 30 years since the advent of micro-rough surfaces, titanium's ability to integrate with bone has not improved significantly. We developed a method to create a unique titanium surface with distinct roughness features at meso-, micro-, and nano-scales. We sought to determine the biological ability of the surface and optimize it for better osseointegration. Commercially pure titanium was acid-etched with sulfuric acid at different temperatures $\left(120,130,140\right.$, and $\left.150{ }^{\circ} \mathrm{C}\right)$. Although only the typical micro-scale compartmental structure was formed during acid-etching at 120 and $130{ }^{\circ} \mathrm{C}$, meso-scale spikes (20-50 $\mu \mathrm{m}$ wide) and nano-scale polymorphic structures as well as micro-scale compartmental structures formed exclusively at 140 and $150^{\circ} \mathrm{C}$. The average surface roughness (Ra) of the three-scale rough surface was 6-12 times greater than that with micro-roughness only, and did not compromise the initial attachment and spreading of osteoblasts despite its considerably increased surface roughness. The new surface promoted osteoblast differentiation and in vivo osseointegration significantly; regression analysis between osteoconductivity and surface variables revealed these effects were highly correlated with the size and density of meso-scale spikes. The overall strength of osseointegration was the greatest when the acid-etching was performed at $140^{\circ} \mathrm{C}$. Thus, we demonstrated that our meso-, micro-, and nano-scale rough titanium surface generates substantially increased osteoconductive and osseointegrative ability over the well-established micro-rough titanium surface. This novel surface is expected to be utilized in dental and various types of orthopedic surgical implants, as well as titanium-based bone engineering scaffolds.

Keywords: acid-etching; bone-implant integration; dental implants; hierarchical morphology; meso-micro-nano roughness; osseointegration; orthopedic implants; titanium surface 


\section{Introduction}

Endosseous implants have become an important treatment modality in medicine and dentistry [1-3]. In particular, orthopedic and dental implants such as plates, screws, and joint reconstructive prostheses are commonly used in the treatment of bone fractures, osteoarthritis, bone defects after tumor resection, and other bone and joint disorders and pathogeneses [4-8]. In the field of dental implants, titanium and its alloys have been used as implant materials for 50 years, ever since the concept of osseointegration was established by Brånemark et al. [9]. In order to achieve better osseointegration, various implant materials have been developed. Surface characteristics of implants—one of the principal factors affecting the process of osseointegration [10] — have been a topic of growing interest for decades. Various titanium surfaces with different micro-scale topography have been developed and studied [11-14]; however, many challenges remain, including difficulties in determining whether one particular implant surface is better than the others [15].

The micron-scale topography of a titanium surface is commonly created by acid-etching, sandblasting, or a combination of both [16]. In addition, the micro-roughness of titanium alloys has also been reported [17]. Numerous studies have shown that such micro-scale topography promotes the adhesion, differentiation, and extracellular matrix formation and mineralization of osteoblasts [18-22]. In contrast, several studies have shown that such osteoblast attachment, spreading, and proliferation can be negatively affected by micro-scale topography $[19,20,23]$. Although it is clear that the micro roughness of the implant surface promotes the overall process of osseointegration, especially in the early phases of healing [24], it remains necessary to further promote differentiation and-more importantly - the potential alleviation of the inhibitory effects on osteoblast attachment, spreading, and proliferation.

Nano-scale design is expected to offer certain benefits for implant materials. It has many advantageous characteristics for cell attachment and spreading [25,26], aiding in the production of more extracellular matrix proteins and enhancing the mechanical interlocking of biomaterials [27]. Moreover, cell-to-cell and cell-to-biological tissue interactions including surface sensing and recognition occur at the molecular level in nano-scale models, as seen in cells interplaying with the nanofeatures of peptide folding, protein complexing, collagen binding, enzymes, and antibodies [28,29]. However, these studies have been conducted using materials other than titanium. It is unclear whether and to what extent the nano-surface improves the osteoconductive and osseointegrative ability of biomaterials [30]; more importantly, nano-scale features have yet to be successfully formed on titanium materials or commercial implant products $[31,32]$. Although reports exist on the creation of nano-scale titanium surfaces $[14,33,34]$, the nano-features did not present distinct or defined appearance. In addition, it is technically difficult to control nano-scale structure, prompting the need for further studies.

To the best of our knowledge, the present study is the first to create meso-scale structures on titanium surfaces. In addition to the well-known micro-scale structure, we successfully created a completely new titanium surface having meso- and nano-scale structure. We hypothesized that this new meso-, micro-, and nano-scale roughness enhances osseointegration by increasing bone-titanium interlocking and further promoting osteoblast differentiation beyond the capacity of surfaces with micro-scale roughness alone. Therefore, the purpose of this study was to investigate the biological and osseointegration capabilities of our newly created meso-, micro-, and nano-scale rough titanium surface and to control and optimize the meso-scale structure for better biological performance.

\section{Results}

\subsection{Morphology of Titanium Surfaces}

Figure 1 shows the morphology of acid-etched titanium surfaces at different temperatures of 120 , 130,140 , and $150{ }^{\circ} \mathrm{C}$ evaluated by scanning electron microscopy (SEM). The greatest contrast was seen in the lowest magnification images (Figure 1A). Titanium surfaces acid-etched at $120^{\circ} \mathrm{C}$ showed no recognizable structures at lowest magnification, whereas those etched at other temperatures showed 
spike-like projecting structures across the surface. The sizes of the spikes were in the meso-scale and ranged from 10 to $80 \mu \mathrm{m}$ according to the SEM images. The density and size of the spikes were greater on titanium surfaces etched at higher temperatures. Higher magnification images clearly showed the spikes more vividly on all surfaces (white arrowheads in B) except for the one etched at $120^{\circ} \mathrm{C}$; moreover, the surface of the spikes began to show microroughness as in other areas of the titanium (Figure 1B). Even higher magnification images configured the microroughness as a compartmental structure consisting of peaks and valleys (Figure 1C). This microrough feature was in common for all surfaces, including the one etched at $120^{\circ} \mathrm{C}$. The highest magnification images revealed nano-scale structures exclusively formed on titanium surfaces etched at $130{ }^{\circ} \mathrm{C}$ or higher (Figure 1D). Nano-scale structures were not observed on $120^{\circ} \mathrm{C}$ acid-etched titanium, even at the highest magnification. Nanofeature was polymorphic, including but not limited to nano-ridge, nano-nodule, nano-pillar, and nano-compartmental structures (white arrowheads in Figure 1D). Thus, we discovered new titanium surfaces with distinct morphology simultaneously at three different levels of meso-, micro-, and nano-scales.

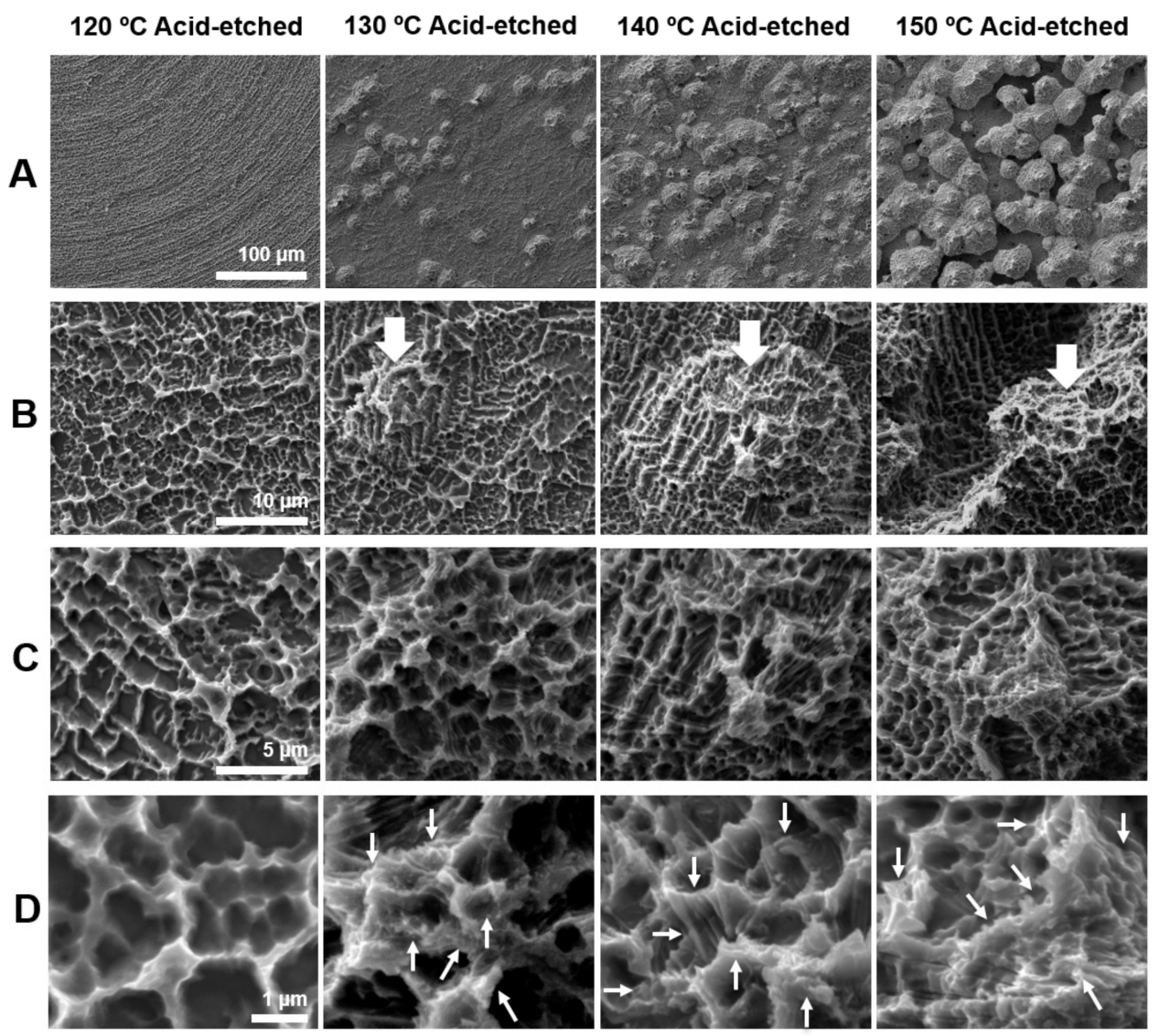

Figure 1. Surface morphology of the titanium disks used in this study. Scanning electron microscopy (SEM) photographs showing surface roughness after acid-etching $\left(\mathrm{H}_{2} \mathrm{SO}_{4}\right)$ at $120,130,140$, and $150{ }^{\circ} \mathrm{C}$.

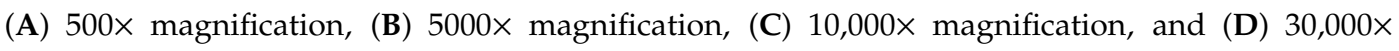
magnification. Scale bar $=(A) 100 \mu \mathrm{m}$, (B) $10 \mu \mathrm{m},(C) 5 \mu \mathrm{m}$, and (D) $1 \mu \mathrm{m}$.

\subsection{Roughness Characteristics of Titanium Surfaces}

Following qualitative observation by SEM, we further characterized the three-dimensional (3-D) morphology of the titanium surfaces by roughness profiling. Figure $2 \mathrm{~A}$ is a side-by-side presentation of the SEM images of the four different titanium surfaces and the 3-D color-contrasted images created from the corresponding SEM images. Confirming the SEM observations, titanium surfaces acid-etched at $130{ }^{\circ} \mathrm{C}$ or higher showed meso-scale spike-like projections, with their density and size generally increasing with temperature during acid-etching. Interestingly, the density of the meso-spikes appeared 
to plateau at $140{ }^{\circ} \mathrm{C}$, whereas their size continued to increase. Due to the maximally increased size of the spikes, as well as their substantial density, the inter-spike spaces were less on the $150^{\circ} \mathrm{C}$-acid-etched surface than on the $140{ }^{\circ} \mathrm{C}$-acid-etched surface.
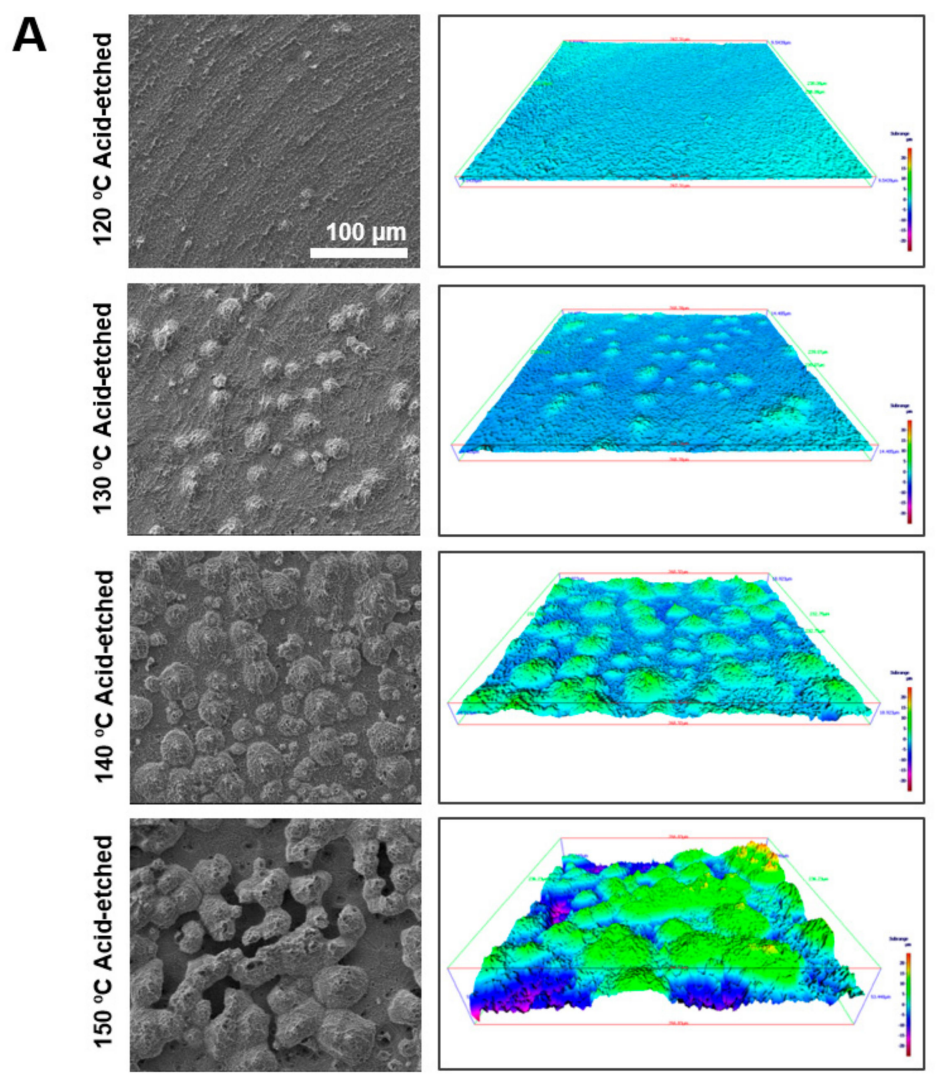

B

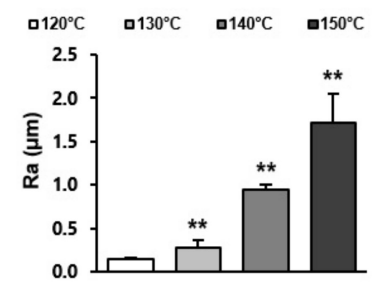

C
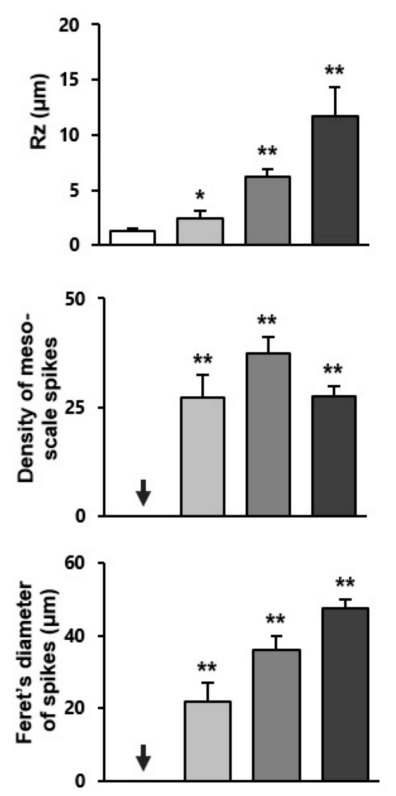

Figure 2. Three-dimensional profile and quantitative topographical evaluations of titanium surfaces. (A) Three-dimensional scanning electron microscopy (3D-SEM) images were built by SEM images. (B) Profile analysis: Ra (average roughness of profile) and Rz (the peak-to-valley height of the roughness profile within a sampling length) were evaluated. (C) The number of meso-scale spikes and Feret's diameter of spikes were measured. Each value represents the mean \pm standard deviation of three sites on the four different surfaces $(n=5) .{ }^{*} p<0.05,{ }^{* *} p<0.01$, with a statistically significant difference when compared to the $120^{\circ} \mathrm{C}$ acid-etched surface.

Figure 2B,C shows the quantification of roughness values. The average roughness ( $\mathrm{Ra}$ ) increased in correlation with the acid-etching temperature. The increase was more significant when the temperature rose from 130 to $140{ }^{\circ} \mathrm{C}$. The Ra of the $140{ }^{\circ} \mathrm{C}$ - and $150{ }^{\circ} \mathrm{C}$-acid-etched surfaces was 6 and 12 times greater, respectively, than the $120^{\circ} \mathrm{C}$-acid-etched surface. The peak-to-valley roughness (Rz) also increased in correlation with temperature. Supporting the observation mentioned earlier, the density of the meso-scale spikes increased with the acid-etching temperature and plateaued at $140{ }^{\circ} \mathrm{C}$, whereas their Feret's diameter continued to increase until the temperature reached $150{ }^{\circ} \mathrm{C}$. The sizes of the meso-spikes ranged from 20 to $50 \mu \mathrm{m}$ according to the Feret's diameters of the spikes, confirming the generation of meso-scale structures.

\subsection{Cell Attachment and Spreading Behavior of Osteoblasts}

The number of osteoblasts attached to titanium surfaces during the initial stage of culture was evaluated by water soluble tetrazolium salts-1 (WST-1) assay $24 \mathrm{~h}$ after seeding (Figure 3A). There were no significant differences between the different temperatures. Low-magnification confocal microscopy images showing a similar quantity of cells confirmed the WST-1 results (Figure 3B). 


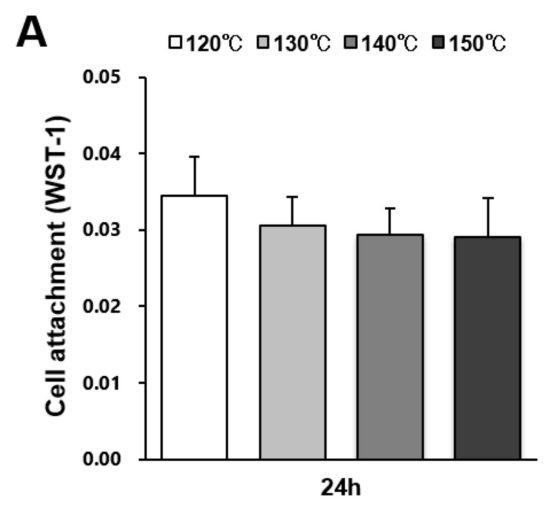

B
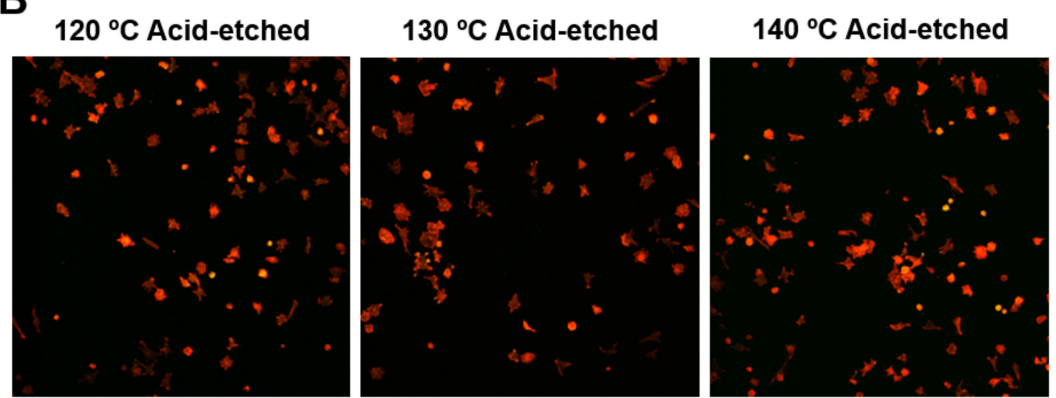

$150^{\circ} \mathrm{C}$ Acid-etched

Figure 3. Attachment of osteoblasts on titanium surfaces acid-etched at different temperatures. (A) Number of cells attached to each titanium surface during a $24 \mathrm{~h}$ incubation, evaluated by a WST-1 assay. No statistically significant differences among the different surfaces were detected. Each value represents the mean \pm standard deviation. (B) Initial spread of osteoblasts $24 \mathrm{~h}$ after seeding on titanium surfaces. Representative confocal microscopy images of cells stained with rhodamine phalloidin for actin filaments (red) and anti-vinculin for vinculin (green).

We next examined the spreading behavior of osteoblasts using higher magnification confocal microscopy images (Figure 4A,B). Cells appeared larger on titanium surfaces acid-etched at higher temperatures. In addition to the increased size of cells, the lamellipodia- and filopodia-like cytoskeletal projections were more advanced on these surfaces. These observations were confirmed by cytomorphometry results showing the increased area, perimeter, and Feret's diameter of the cells. Image-based densitometry showed that the expression of cytoskeletal actin and vinculin-a focal adhesion protein-tended to increase with temperature (Figure 4C). 

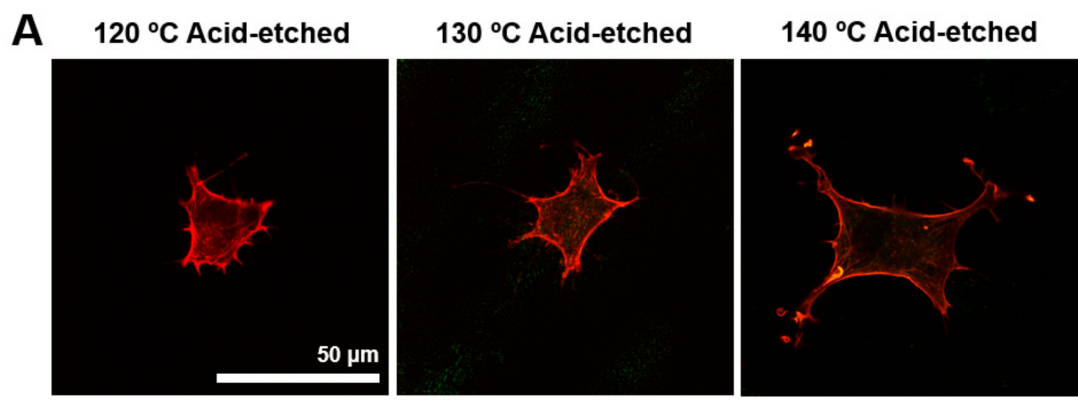

$150^{\circ} \mathrm{C}$ Acid-etched
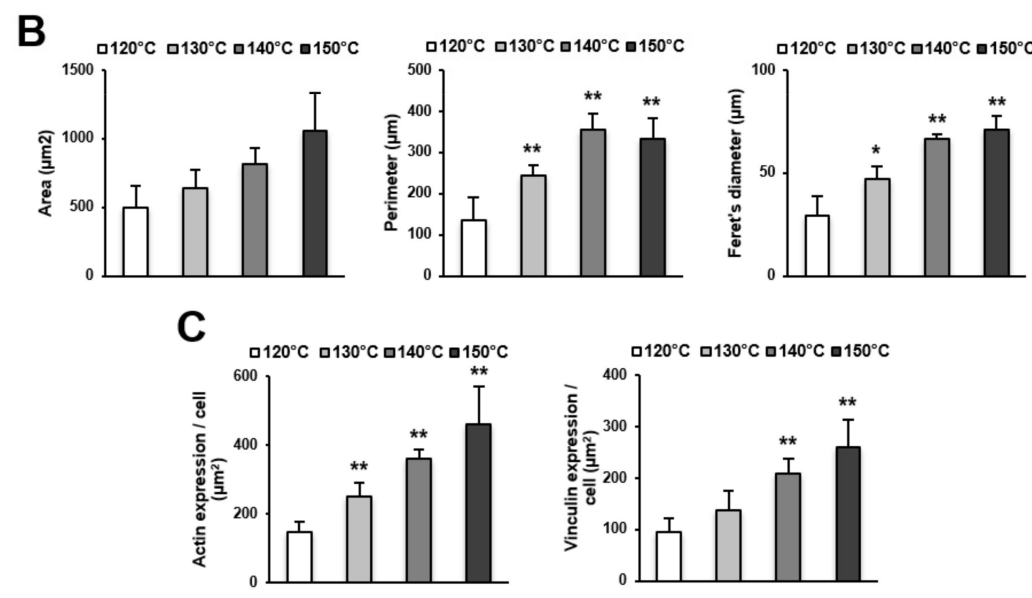

Figure 4. Representative confocal microscopy images of the spreading behavior of osteoblasts $24 \mathrm{~h}$ after seeding on acid-etched titanium discs at different temperatures. (A) The cells were stained with rhodamine phalloidin for actin filaments (red) and anti-vinculin antibody for vinculin (green). Scale bar $=50 \mu \mathrm{m}$. (B) Histograms for cytomorphometric parameters measured from the images. (C) The expression levels of actin and vinculin were semiquantified using the confocal microscopy images. Data are mean \pm standard deviation $(n=5)$ for panels $(B, C) .{ }^{*} p<0.05,{ }^{* *} p<0.01$, with a statistically significant difference when compared to the $120^{\circ} \mathrm{C}$ acid-etched surface.

\subsection{Osteoblast Differentiation}

Osteoblast differentiation was examined by alkaline phosphatase (ALP) activity, calcium deposition, and the expression of osteoblastic genes. ALP activity and calcium deposition increased with temperature (Figure 5A,B). The expression of osteopontin $(\mathrm{Opn})$ increased on the surfaces acid-etched at higher temperatures on both day 7 (early stage of culture) and 14 (later stage of culture) (Figure 6A,B). This upregulated trend with increasing temperature was similar for osteocalcin $(\mathrm{Ocn})$ expression, indicating that the three-scale roughness not only accelerated the differentiation of osteoblasts but also elevated the degree and probability of differentiation. 
A

$\square 120^{\circ} \mathrm{C} \quad \square 130^{\circ} \mathrm{C} \quad \square 140^{\circ} \mathrm{C} \quad \square 150^{\circ} \mathrm{C}$

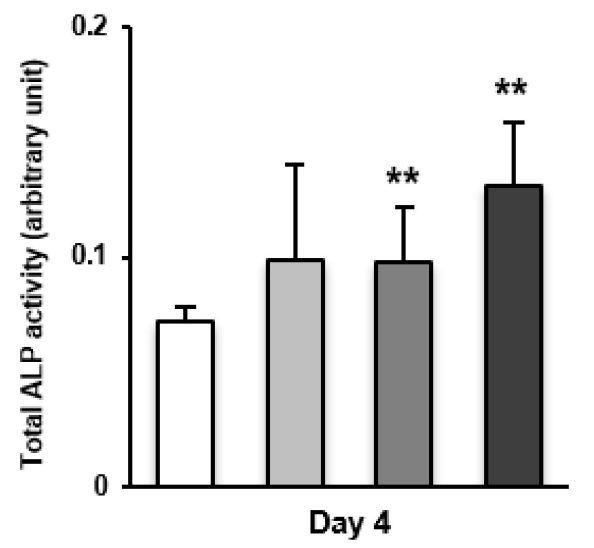

B

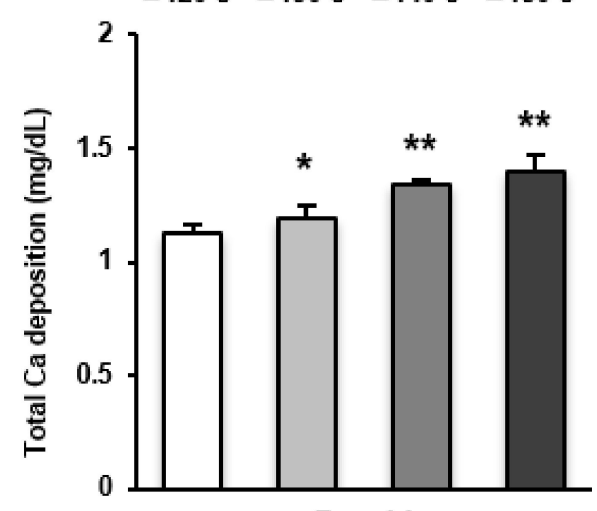

Day 14

Figure 5. Osteoblast differentiation on titanium surfaces etched at different temperatures. (A) Alkaline phosphatase (ALP) activity at day 4, colorimetrically quantified and standardized relative to cell number. (B) Total calcium deposition at day 14 , as measured using a colorimetry-based method. Each value represents the mean \pm standard deviation of triplicate experiments $(n=3)$. ${ }^{*} p<0.05,{ }^{* *} p<0.01$, with a statistically significant difference when compared to the $120^{\circ} \mathrm{C}$ acid-etched surface.

\section{Osteopontin}

$\square 120^{\circ} \mathrm{C} \square 130^{\circ} \mathrm{C} \square 140^{\circ} \mathrm{C} \square 150^{\circ} \mathrm{C}$

\section{A}
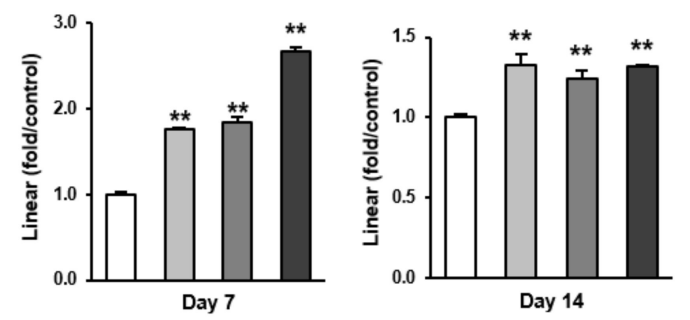

B

Osteocalcin

$\square 120^{\circ} \mathrm{C} \square 130^{\circ} \mathrm{C} \square 140^{\circ} \mathrm{C} \square 150^{\circ} \mathrm{C}$
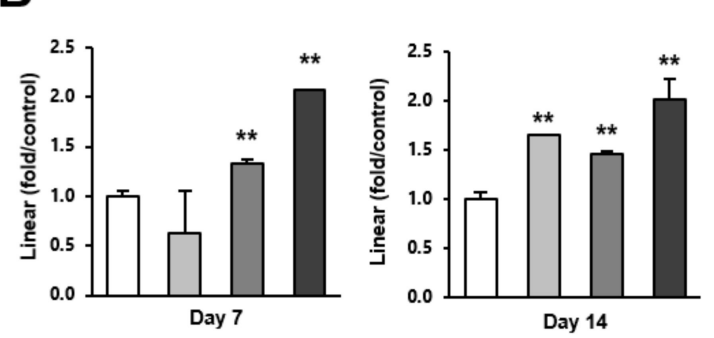

Figure 6. Gene expression levels of selected markers quantified via real-time qPCR. The osteogenic markers (A) osteopontin and (B) osteocalcin were analyzed. Total RNA was isolated at 7 and 14 days using osteoblastic cell cultures on titanium surfaces acid-etched at different temperatures. Relative expression levels ( $2^{-\Delta \Delta \mathrm{Ct}}$ values) of the genes of interest were normalized to that of the housekeeping gene glyceraldehyde-3-phosphate dehydrogenase (Gapdh). Each value represents the mean \pm standard deviation of triplicate experiments $(n=3) .{ }^{* *} p<0.01$, with a statistically significant difference when compared to the $120^{\circ} \mathrm{C}$ acid-etched surface.

\subsection{Biomechanical Strength of Bone-Implant Integration}

The strength of bone-titanium integration was measured by push-in value at week 2 (Figure 7). The push-in value increased with temperature during acid-etching and peaked at $140{ }^{\circ} \mathrm{C}$. The push-in value of the $140^{\circ} \mathrm{C}$ acid-etched surface was 2.3 times greater than that of the $120^{\circ} \mathrm{C}$-acid-etched surface. 


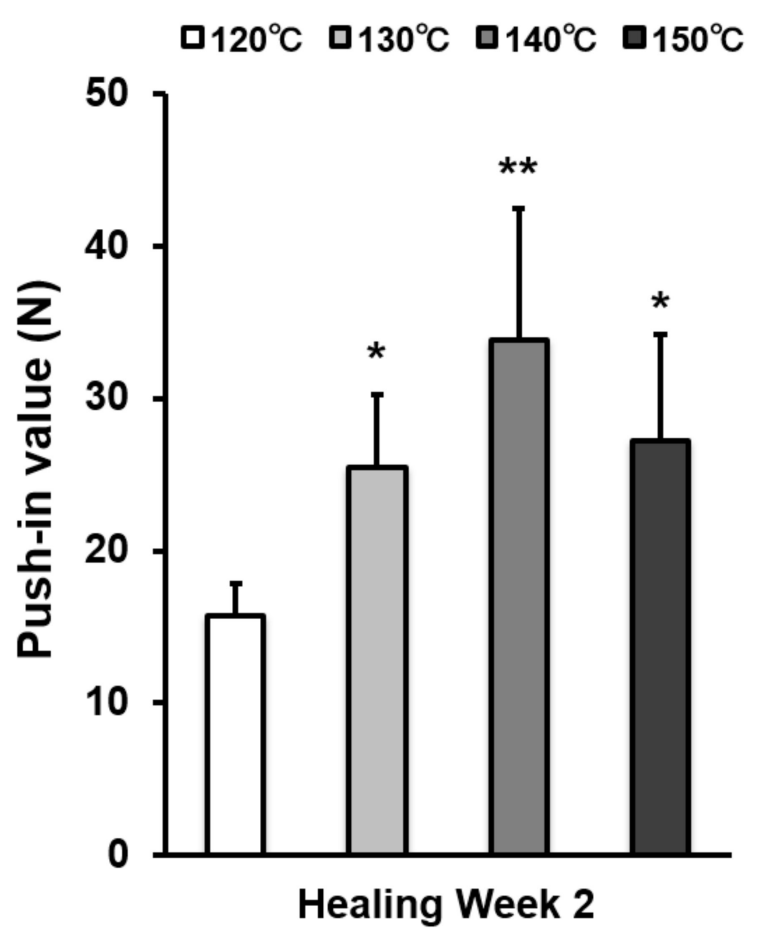

Figure 7. The strength of implant anchorage in bone, evaluated by the biomechanical push-in test in a rat femur model. Each bar represents mean \pm standard deviation of titanium surfaces acid-etched at different temperatures $(n=6)$. ${ }^{*} p<0.05,{ }^{* *} p<0.01$, with a statistically significant difference when compared to the $120^{\circ} \mathrm{C}$ acid-etched surface.

\subsection{Topographical Determinants for Osteoconductivity and Osseointegration}

We sought potential topographical variables to determine the osteoconductivity and osseointegration abilities of our uniquely-created titanium surfaces. ALP activity (Figure 8A-C) and push-in values (Figure 8D-F) were plotted against the different surface variables' Ra, number of meso-spikes, and Feret's diameter of meso-spikes to extract their potential correlation (Figure 8). ALP activity increased linearly with all three surface variables-the higher the magnitude of the surface variables, the higher the ALP activity. The coefficient of determination $\left(R^{2}\right)$ was found between the ALP activity and the values for Feret's diameter of the meso-spikes. The push-in value correlated significantly with the number of meso-spikes and their Feret's diameters but not with Ra. Of note, the push-in values correlated with the number of meso-spikes with a remarkably high coefficient of determination. 
A

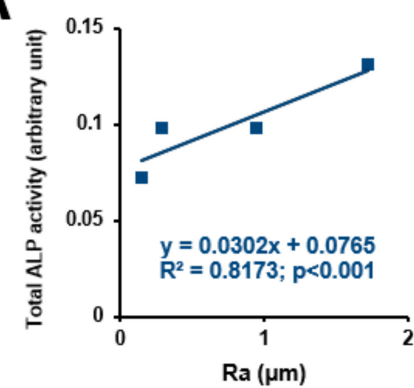

D

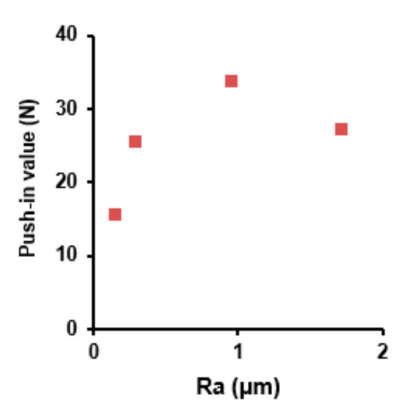

B

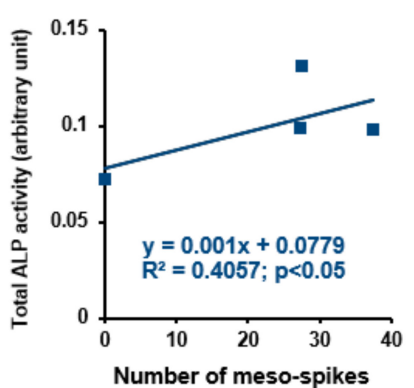

E

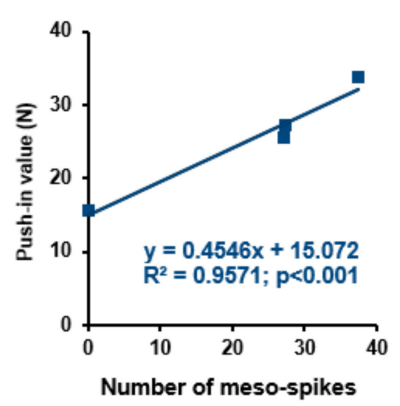

C

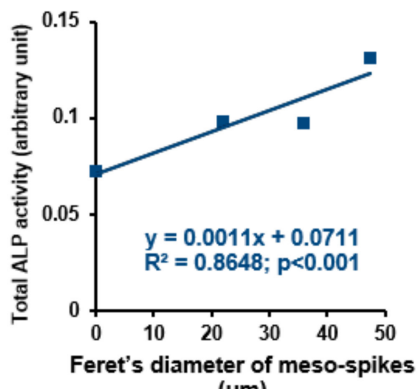

$\mathbf{F}$

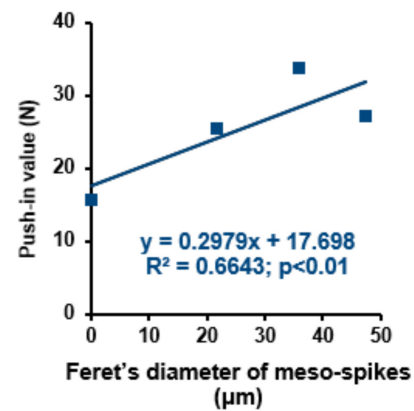

Figure 8. Correlation between differentiation ability or push-in value and each surface roughness parameter. Total ALP activity after incubation for 4 days plotted against the average roughness (Ra) of the acid-etched titanium surfaces, showing a significant linear correlation (A). Number of meso-spikes (B) and Feret's diameter of meso-spikes (C) plotted against total ALP activity at day 4, showing a significant linear correlation between ALP activity and number of meso-spikes (B) and between ALP activity and Feret's diameter of meso-spikes (C). Push-in value plotted against Ra, showing no significant correlation (D). Number of meso-spikes (E) and Feret's diameter of meso-spikes (F) plotted against push-in value, showing a significant linear correlation between push-in value and number of meso-spikes (E) and between push-in value and Feret's diameter of meso-spikes (F).

\section{Discussion}

In the present study, we created the surface topography of three phases-meso-, micro-, and nano-scale- of a rough titanium surface using a simple and effective method. Across the surface of the acid-etched titanium, the micro-scale roughness was revealed in SEM images 1-5 $\mu \mathrm{m}$ wide. The meso-scale roughness was illustrated in three-dimensional scanning electron microscopy (3D-SEM) images 10-50 $\mu \mathrm{m}$ wide and 10-20 $\mu \mathrm{m}$ deep. As the temperature of the acid-etching rose, the height and width of the meso-scale structure as well as the number of structures increased. In addition, on the surface of the meso-scale structure, the nano-scale structure was observed with a width of approximately $100 \mathrm{~nm}$ and a rounded tip.

Results of our in vitro study showed a similar rate of osteoblast proliferation based on the different temperatures applied to acid-etched groups. In contrast, cell differentiation increased in the high temperature group. The rough surface induced osteoblastic phenotypes through increased ALP activity and upregulation of the expression levels of bone-related genes [35,36]. The results of the present study also showed that cell differentiation rose proportionally with the rise in temperature of acid-etching - in other words, with the increase in surface roughness. Moreover, the osteoblasts interacted with the titanium surface through integrin [37]. The promotion of differentiation at an early stage was indicated by confocal microscopy after $24 \mathrm{~h}$ of culture. These results agree with the behavior of osteoblasts that has been widely identified in previous studies [38-41]. In principle, the rates of osteoblast proliferation and differentiation are inversely correlated [38,41], i.e., when osteoblasts are robust in proliferative activity, their differentiation slows down and vice versa. This is partly because opposing growth factors regulate osteoblast proliferation and differentiation [42,43]. This biological discrepancy also applies to osteogenic cells at biomaterial and implant surfaces [19,44]. 
It has been reported that the proliferation of osteoblasts on roughened titanium surfaces is one-third to one-fifth of that observed on machined titanium surfaces $[20,35,45,46]$. It is notable that meso-, micro-, and nano-scale rough titanium (especially the $140{ }^{\circ} \mathrm{C}$ and $150{ }^{\circ} \mathrm{C}$ groups) did not reduce the rate of proliferation compared to the $120^{\circ} \mathrm{C}$ acid-etched surface, although it did enable faster differentiation. Accelerating bone formation around implants is very important for clinical applications in both dental and orthopedic fields. In addition to the results of our in vitro study mentioned above, upregulated osteogenic gene expression was observed on the high temperature acid-etched surfaces, i.e., meso-, micro-, and nano-scale rough titanium. The late-stage markers such as Opn and Ocn were significantly upregulated, not only on day 7 , but also on day 14 . These gene expression results are also consistent with the mineralization assay results in vitro. The mineralization culture started on day 14 in our culture system. The present results indicate that differentiation and maturation of the osteoblasts was promoted. Previous studies report that nano-nodular titanium surfaces exhibit osteoblast proliferation rates similar to those observed in the present study, despite the substantial increase in overall surface roughness [12,47]. Furthermore, it has been reported that nano-scale structure also promotes osteoblast differentiation $[25,26]$. The mechanism underlying this observation requires further study; however, the rounded peaks of the nano-scale structure (compared to the sharp peaks typically seen on acid-etch-created rough titanium) might minimize the negative impact on osteoblast proliferation.

The strength of the integration was evaluated by an in vivo push-in test. The results showed that the strength was significantly increased as the temperature of the acid etching rose. This trend reached a peak at $140{ }^{\circ} \mathrm{C}$ and slightly decreased at $150{ }^{\circ} \mathrm{C}$. The biological advantage of meso-, micro-, and nano-scale rough titanium surface, as consequently shown in the enhanced strength of bone-titanium integration, may not be explained solely by the increased surface area of titanium and increased bone-titanium interlocking. This corroborated the in vitro results that osteoblast proliferation and differentiation were upregulated on the meso-, micro-, and nano-scale rough titanium surface, indicating that bone-implant integration was not merely expedited but also enhanced. We assume that the combined effect of the increased bone-titanium mechanical interlocking and the enhanced function of osteoblasts is responsible for the enhanced strength of bone-titanium integration in which the nano-scale polymorphic structures regulated osteoblast function but not the mechanical interlocking. Moreover, in order to investigate the influence of each surface parameter on the differentiation or integration ability, we calculated a correlation. The result indicated that Ra showed positive correlation between the differentiation ability. It is well known that rougher surfaces induce osteoblast differentiation $[20,44]$. Interestingly, the number and size of the meso-scale structures, i.e., spike structure, had an effect on osseointegration ability. Therefore, it is assumed that the meso-scale structure not only improves the osseointegration ability as evaluated by the push-in test but also strengthens the mechanical interlocking of bone. Further research should be undertaken to reveal the physical and chemical properties involved in these processes.

In this study, we did not perform any morphological or biological analyses involving machined surfaces. The main focus of this study was the further enhancement of the rough titanium surface. This is because machined surface titanium implants are currently rarely used in clinics. The machined surface does not have any specific morphological feature apart from a pattern of parallel traces generated by the machining process $[19,48]$. It has been shown that titanium implants used in clinical practices can integrate into the bone much better when the implant surface shows some micro-roughness rather than being machined [49-52]. In addition, implant threads with micro-rough surfaces are also known to have a stronger mechanical interlocking force than those with the machined surface [52-55]. Evaluation of various previously reported morphological, physiochemical, and biological studies on machined and acid-etched surfaces $[20,37,44,56-60]$ revealed that the three-scale rough surface generated in this study is clearly different from the machined surface.

The mechanism underlying the formation of the three-scale roughness needs to be studied further. The surface was made by a subtraction method via acid-etching. Different than the conventional 
micro-rough surface, the surface presented here has meso- and nano-structures. The procedure used in this study was simple, and no chemical other than sulfuric acid was used. Therefore, we postulate that a similar chemical reaction as in the conventional acid-etching occurred during the formation of the three-scale roughness. However, the mechanism underlying the typical micro-rough titanium surface made by simple acid-etching and most commonly used in dental implants remains unknown as well.

Here, we introduced an alternative titanium rough surface created by a simple method that demonstrated an improvement in osseointegration ability. This meso-, micro-, and nano-scale rough titanium is unique in terms of promoting osteoblast differentiation while maintaining proliferation at the same rate as the $120^{\circ} \mathrm{C}$ acid-etched surface. Our results suggest that improvements in future implants are possible by optimizing meso-, micro-, and nano-scale surface topography. Furthermore, the technique would be applicable in clinical settings because the process is simple and does not require additional material. That being said, further studies to optimize the meso-, micro-, and nano-scale topography are necessary to increase their potential for routine use in medical and dental treatments. The surface presented in this study is novel and ground-breaking because of its three-scale structures that are simultaneously formed and its very simple, one-step manufacturing process. Therefore, this technology is expected to be utilized in dental and various types of orthopedic surgical implants, as well as titanium-based bone engineering scaffolds. Studies involving mid- and large-scale animals and human clinical trials are warranted.

\section{Materials and Methods}

\subsection{Titanium Samples and Surface Analysis}

Titanium samples were prepared for cylindrical implants (1 $\mathrm{mm}$ in diameter, $2 \mathrm{~mm}$ in length) and disks (20 mm in diameter, $1.5 \mathrm{~mm}$ in thickness) of commercially pure grade 2 titanium $(\mathrm{N}: \leq 0.03 \%, \mathrm{C}$ : $\leq 0.08 \%, \mathrm{H}: \leq 0.013 \%$, Fe: $\leq 0.20 \%$, O: $\leq 0.15 \%$, Ti: Balance) (Nishimura Kinzoku Co., Sabae, Fukui, Japan). Titanium surfaces were acid-etched with $67 \% \mathrm{H}_{2} \mathrm{SO}_{4}$ for $75 \mathrm{~s}$ at $120,130,140$, and $150{ }^{\circ} \mathrm{C}$. The surface morphology of these surfaces was examined by scanning electron microscopy (SEM; XL30; Phillips, Eindhoven, Netherlands). Three-dimensional scanning electron microscopy (3D-SEM) images were built from SEM images using photogrammetry technique software (MeX; Alicona Imaging $\mathrm{GmbH}$, Raaba/Graz, Austria). The average roughness (Ra) and the peak-to-valley height roughness (Rz) were calculated. The mean number of meso-scale spike structures per unit $\left(/ 10^{4} \mu \mathrm{m}^{2}\right)$ and their diameters were examined using an image analyzer (ImageJ; NIH, Bethesda, MD, USA).

\subsection{Osteoblastic Cell Culture}

As established previously [61], bone marrow cells isolated from the femurs of 8-week-old male Sprague-Dawley rats were placed into alpha-modified Eagle's medium supplemented with $15 \%$ fetal bovine serum, $50 \mathrm{mg} / \mathrm{mL}$ ascorbic acid, $10 \mathrm{mM}$ Na- $\beta$-glycerophosphate, $10^{-8} \mathrm{M}$ dexamethasone, and antibiotic-antimycotic solution. Cells were incubated in a humidified atmosphere of $95 \%$ air and $5 \% \mathrm{CO}_{2}$ at $37^{\circ} \mathrm{C}$. At $80 \%$ confluency, the cells were detached using $0.25 \%$ trypsin- $1 \mathrm{mM}$ EDTA- $4 \mathrm{Na}$ and seeded onto the titanium disks at a density of $3 \times 10^{4} \mathrm{cells} / \mathrm{cm}^{2}$. The culture medium was renewed every 3 days.

\subsection{Cell Attachment Assay}

Initial attachment of cells was evaluated by measuring the number of cells attached to titanium disks after $24 \mathrm{~h}$ of incubation using WST-1-based colorimetry (WST-1; Roche Applied Science, Mannheim, Germany). The culture well was incubated with $100 \mu \mathrm{L}$ WST- 1 reagent at $37^{\circ} \mathrm{C}$ for $4 \mathrm{~h}$. The amount of formazan produced was measured using an enzyme-linked immunosorbent assay (ELISA) plate reader (Synergy HT; Bio Tek Instruments, Inc., Winooski, VT, USA) at $450 \mathrm{~nm}$. 


\subsection{Cell Morphology and Morphometry}

Confocal laser scanning microscopy (TCS SP5; Leica, Wetzlar, Germany) was used to examine cell morphology and cytoskeletal arrangement of osteoblasts seeded onto the titanium surfaces. After $24 \mathrm{~h}$ of culture, cells were fixed in $10 \%$ formalin solution and stained using the fluorescent dye rhodamine phalloidin (actin filament, red color; R415; Molecular Probes, Eugene, OR, USA). The area, perimeter, and Ferret's diameter of cells were quantified using an image analyzer (ImageJ).

\subsection{Vinculin and Actin Expression Analysis}

The expression and localization of the focal adhesion protein vinculin were analyzed by microscopy image-based observation and densitometry at $24 \mathrm{~h}$ of culture. During preparation for the confocal microscopy analysis, the cultures were also immunochemically stained with mouse anti-vinculin monoclonal antibody (green color; ab11149; Abcam, Cambridge, MA, USA), followed by FITC-conjugated anti-mouse secondary antibody (Abcam). The level of vinculin expression was quantified as a pixel-based density using an image analyzer (ImageJ). Densitometry was also applied to quantify the expression of actin filaments in the same manner using the images stained with rhodamine phalloidin.

\subsection{Alkaline Phosphatase (ALP) Activity}

The ALP activity of osteoblasts was examined at day 4 using a colorimetry-based assay. The culture was rinsed with double-distilled water $\left(\mathrm{ddH}_{2} \mathrm{O}\right)$ and treated with $250 \mu \mathrm{L}$ p-nitrophenylphosphate (LabAssay ALP, Wako Pure Chemicals, Richmond, VA, USA) and further incubated at $37^{\circ} \mathrm{C}$ for $15 \mathrm{~min}$. The ALP activity was evaluated as the amount of nitrophenol released through the enzymatic reaction and measured at a wavelength of $405 \mathrm{~nm}$ using an ELISA plate reader (Synergy HT).

\subsection{Mineralization Assay}

The mineralization capability of cultured osteoblasts was examined by colorimetry-based quantification of calcium deposition at day 14. The cultures were washed with PBS and incubated overnight in $1 \mathrm{~mL}$ of $0.5 \mathrm{mM} \mathrm{HCl}$ solution with gentle shaking. The solution was mixed with $o$-cresolphthalein complexone in an alkaline medium (calcium binding and buffer reagent; Sigma-Aldrich, St. Louis, MO, USA) to produce a red calcium cresolphthalein complexone complex. Color intensity was measured by an ELISA plate reader (Synergy HT) at $575 \mathrm{~nm}$ absorbance.

\subsection{Real-Time Quantitativepcr (Real-Time qPCR)}

Total RNA was isolated at days 7 and 14 using an RNeasy Plus Mini Kit (Qiagen, Hilden, Germany) and complementary DNA (cDNA) was made as described previously [62]. Real-time qPCR was performed in triplicate for each sample with LC480 SYBR Green I Master (Roche Diagnostics, Indianapolis, IN, USA) using universal cycling conditions on a LightCycler 480 (Roche) [63]. A total of 55 cycles were executed and the second derivative $C q$ value determination method was used to compare fold-differences. For PCR amplification, the target-specific PCR primers for osteopontin (Opn), osteocalcin (Ocn), and glyceraldehyde-3-phosphate dehydrogenase (Gapdh), a housekeeping gene, were used (Table 1). Analysis of relative gene expression was performed with the $2^{-\Delta \Delta \mathrm{Ct}}$ method [19]. The expression levels of various genes were expressed as fold differences in gene expression relative to that of the $120^{\circ} \mathrm{C}$ acid-etched surface. 
Table 1. Primer sequences for real-time qPCR. Opn: osteopontin, Ocn: osteocalcin.

\begin{tabular}{lll}
\hline Gapdh & Forward & AACCCATCACCATCTTCCAGG \\
& Reverse & GCCTTCTCCATGGTGGTGAA \\
Opn & Forward & GACAGCAACGGGAAGACC \\
& Reverse & CAGGCTGGCTTTGGAACT \\
Ocn & Forward & GAGGGCAGTAAGGTGGTGAA \\
& Reverse & CGTCCTGGAAGCCAATGTG \\
\hline
\end{tabular}

\subsection{Implant Surgery}

Eight-week-old male Sprague-Dawley rats were anesthetized with $1 \%-2 \%$ isoflurane inhalation. After their legs were shaved and scrubbed with $10 \%$ povidone-iodine solution, the distal aspects of the femurs were carefully exposed via skin incision and muscle dissection. The flat surfaces of the distal femurs were selected for implant placement. The implant site was prepared $9 \mathrm{~mm}$ from the distal edge of the femur by drilling with a $0.8 \mathrm{~mm}$ round burr and enlarged using reamers (\#ISO 090 and 100). Profuse irrigation with sterile isotonic saline solution was used for cooling and cleaning. One titanium cylindrical implant, acid-etched at different temperatures ( $1 \mathrm{~mm}$ in diameter and $2 \mathrm{~mm}$ in length), was placed into the prepared hole. Surgical sites were then closed in layers. Muscle and skin were sutured separately with resorbable suture thread. The University of California at Los Angeles (UCLA) Chancellor's Animal Research Committee approved this protocol (ARC \#2005-175-41E, approved on 30 January 2018) and all experimentation was performed in accordance with the United States Department of Agriculture (USDA) guidelines on animal research.

\subsection{Biomechanical Implant Push-In Test}

The biomechanical implant push-in test was used to assess the biomechanical strength of bone-implant integration, as described previously $[48,64]$. At week 2 of healing, femurs containing a cylindrical implant were harvested and embedded into auto-polymerizing resin at the top surface of the implant level. A micro-CT machine ( $\mu \mathrm{CT} 40$; SancroMedica, Bassersdorf, Switzerland) was used to confirm that the implants were free from cortical bone support from the lateral and bottom sides of the implant. The testing machine (Instron 5544 electromechanical testing system; Instron, Norwood, MA, USA) equipped with a $2000 \mathrm{~N}$ load cell and a pushing rod (diameter $1 / 40.8 \mathrm{~mm}$ ) was used to load the implant vertically downward at a crosshead speed of $1 \mathrm{~mm} / \mathrm{min}$. The push-in value was determined by measuring the peak of the load-displacement curve.

\subsection{Statistical Analysis}

We used three samples for the cell culture studies, except for the surface analysis which was evaluated in five samples; five were used for cell morphometry and the number of implants for the implant push-in test was six. Statistical analysis was carried out using SPSS Version 22.0 (IBM Corp., Armonk, NY, USA). One-way ANOVA was used to examine the effects of titanium surfaces acid-etched at different temperatures; $p<0.05$ was considered statistically significant. Correlations between total ALP activity and titanium surface topography, and push-in value and surface topography were examined; regression formulas were determined by least-squares mean approximation.

\section{Conclusions}

We created a novel titanium surface with meso-, micro-, and nano-scale roughness by employing high temperature acid-etching. This three-scale rough titanium significantly promoted osteoblast differentiation without compromising the attachment and spreading of osteoblasts. Osteoconductivity and osseointegration ability were highly correlated with the size and density of meso-scale spikes. The overall strength of osseointegration was the greatest when the acid-etching was performed at $140{ }^{\circ} \mathrm{C}$, and the strength was 2.3 times greater than that of a titanium surface with micro-scale roughness alone. 
Author Contributions: M.H. (Masakazu Hasegawa) performed experiments and data analysis and drafted the manuscript. J.S. performed data analysis and interpretation, and drafted the manuscript. M.H. (Makoto Hirota) and T.T. performed experiments and interpreted results. M.I. was involved in experimental design and performed the experiments and data analysis. T.I., Y.S., K.K. and H.M. contributed to the interpretation of data and reviewed the manuscript. T.O. was involved in experimental design, data analysis and interpretation, and drafting of the manuscript. All authors discussed the results and commented on the manuscript. All authors have approved the final version of the manuscript.

Funding: This research received no external funding.

Acknowledgments: We would like to thank Editage (www.editage.com) for English language editing.

Conflicts of Interest: The authors declare no conflicts of interest.

\section{Abbreviations}

$\begin{array}{ll}\text { ALP } & \text { Alkaline phosphatase } \\ \text { ANOVA } & \text { One-way analysis of variance } \\ \text { cDNA } & \text { Complementary DNA } \\ \text { ELISA } & \text { Enzyme-linked immunosorbent assay } \\ \text { Gapdh } & \text { Glyceraldehyde-3-phosphate dehydrogenase } \\ \text { Ocn } & \text { Osteocalcin } \\ \text { Opn } & \text { Osteopontin } \\ \text { PCR } & \text { Polymerase chain reaction } \\ \text { SEM } & \text { Scanning electron microscopy } \\ \text { WST } & \text { Water soluble tetrazolium salts }\end{array}$

\section{References}

1. Boylan, M.R.; Chadda, A.; Slover, J.D.; Zuckerman, J.D.; Iorio, R.; Bosco, J.A. Preferred Single-Vendor Program for Total Joint Arthroplasty Implants: Surgeon Adoption, Outcomes, and Cost Savings. J. Bone Jt. Surg. Am. 2019, 101, 1381-1387. [CrossRef]

2. Alexis, I.; Heierle, L.; Hammerle, C.H.F.; Husler, J.; Jung, R.E.; Thoma, D.S. Prospective randomized controlled clinical study comparing two types of two-piece dental implants supporting fixed reconstructions-Results at 5 years of loading. Clin. Oral. Implants Res. 2019. [CrossRef]

3. Wang, M.; Tang, T. Surface treatment strategies to combat implant-related infection from the beginning. J. Orthop. Translat. 2019, 17, 42-54. [CrossRef] [PubMed]

4. Kaur, M.; Singh, K. Review on titanium and titanium based alloys as biomaterials for orthopaedic applications. Mater Sci. Eng. C. Mater. Biol. Appl. 2019, 102, 844-862. [CrossRef] [PubMed]

5. Leno, M.B.; Liu, S.Y.; Chen, C.T.; Liao, H.T. Comparison of functional outcomes and patient-reported satisfaction between titanium and absorbable plates and screws for fixation of mandibular fractures: A one-year prospective study. J. Craniomaxillofac Surg. 2017, 45, 704-709. [CrossRef] [PubMed]

6. Rengaraja, D.; Jagade, M.; Rao, K.; Sonate, R.; Singhal, A. Reconstruction of Maxilla with Titanium Mesh and Fascia Lata-A Case Report. J. Clin. Diagn. Res. 2017, 11, MD03-MD05. [CrossRef] [PubMed]

7. Banakis Hartl, R.M.; Mattingly, J.K.; Greene, N.T.; Jenkins, H.A.; Cass, S.P.; Tollin, D.J. A Preliminary Investigation of the Air-Bone Gap: Changes in Intracochlear Sound Pressure With Air- and Bone-conducted Stimuli After Cochlear Implantation. Otol. Neurotol. 2016, 37, 1291-1299. [CrossRef]

8. Tabuchi, M.; Ikeda, T.; Hirota, M.; Nakagawa, K.; Park, W.; Miyazawa, K.; Goto, S.; Ogawa, T. Effect of UV Photofunctionalization on Biologic and Anchoring Capability of Orthodontic Miniscrews. Int. J. Oral Maxillofac. Implants 2015, 30, 868-879. [CrossRef]

9. Branemark, P.I.; Hansson, B.O.; Adell, R.; Breine, U.; Lindstrom, J.; Hallen, O.; Ohman, A. Osseointegrated implants in the treatment of the edentulous jaw. Experience from a 10-year period. Scand J. Plast Reconstr. Surg. Suppl. 1977, 16, 1-132.

10. Albrektsson, T.; Johansson, C. Osteoinduction, osteoconduction and osseointegration. Eur. Spine J. 2001, 10 (Suppl. 2), S96-S101. [CrossRef]

11. Iwasa, F.; Tsukimura, N.; Sugita, Y.; Kanuru, R.K.; Kubo, K.; Hasnain, H.; Att, W.; Ogawa, T. $\mathrm{TiO} 2$ micro-nano-hybrid surface to alleviate biological aging of UV-photofunctionalized titanium. Int. J. Nanomedicine 2011, 6, 1327-1341. [CrossRef] [PubMed] 
12. Kubo, K.; Tsukimura, N.; Iwasa, F.; Ueno, T.; Saruwatari, L.; Aita, H.; Chiou, W.A.; Ogawa, T. Cellular behavior on $\mathrm{TiO} 2$ nanonodular structures in a micro-to-nanoscale hierarchy model. Biomaterials 2009, 30, 5319-5329. [CrossRef] [PubMed]

13. Marenzi, G.; Spagnuolo, G.; Sammartino, J.C.; Gasparro, R.; Rebaudi, A.; Salerno, M. Micro-Scale Surface Patterning of Titanium Dental Implants by Anodization in the Presence of Modifying Salts. Materials 2019, 12, 1753. [CrossRef] [PubMed]

14. Souza, J.C.M.; Sordi, M.B.; Kanazawa, M.; Ravindran, S.; Henriques, B.; Silva, F.S.; Aparicio, C.; Cooper, L.F. Nano-scale modification of titanium implant surfaces to enhance osseointegration. Acta Biomater. 2019, 94, 112-131. [CrossRef]

15. Bachle, M.; Kohal, R.J. A systematic review of the influence of different titanium surfaces on proliferation, differentiation and protein synthesis of osteoblast-like MG63 cells. Clin. Oral Implants Res. 2004, 15, 683-692. [CrossRef]

16. Meng, H.W.; Chien, E.Y.; Chien, H.H. Dental implant bioactive surface modifications and their effects on osseointegration: A review. Biomark Res. 2016, 4, 24. [CrossRef]

17. Berni, M.; Lopomo, N.; Marchiori, G.; Gambardella, A.; Boi, M.; Bianchi, M.; Visani, A.; Pavan, P.; Russo, A.; Marcacci, M. Tribological characterization of zirconia coatings deposited on Ti6Al4V components for orthopedic applications. Mater. Sci. Eng. C. Mater. Biol. Appl. 2016, 62, 643-655. [CrossRef]

18. Zizzari, V.L.; Marconi, G.D.; De Colli, M.; Zara, S.; Zavan, B.; Salini, V.; Fontana, A.; Cataldi, A.; Piattelli, A. In Vitro Behavior of Primary Human Osteoblasts Onto Microrough Titanium Surface. Implant Dent. 2015, 24, 377-383. [CrossRef]

19. Saruta, J.; Sato, N.; Ishijima, M.; Okubo, T.; Hirota, M.; Ogawa, T. Disproportionate Effect of Sub-Micron Topography on Osteoconductive Capability of Titanium. Int. J. Mol. Sci. 2019, 20, 4027. [CrossRef]

20. Aita, H.; Hori, N.; Takeuchi, M.; Suzuki, T.; Yamada, M.; Anpo, M.; Ogawa, T. The effect of ultraviolet functionalization of titanium on integration with bone. Biomaterials 2009, 30, 1015-1025. [CrossRef]

21. Mesquita, P.; Gomes Pde, S.; Sampaio, P.; Juodzbalys, G.; Afonso, A.; Fernandes, M.H. Surface properties and osteoblastic cytocompatibility of two blasted and Acid-etched titanium implant systems with distinct microtopography. J. Oral Maxillofac. Res. 2012, 3, e4. [CrossRef] [PubMed]

22. Bell, B.F.; Schuler, M.; Tosatti, S.; Textor, M.; Schwartz, Z.; Boyan, B.D. Osteoblast response to titanium surfaces functionalized with extracellular matrix peptide biomimetics. Clin. Oral. Implants Res. 2011, 22, 865-872. [CrossRef] [PubMed]

23. Schwartz, Z.; Olivares-Navarrete, R.; Wieland, M.; Cochran, D.L.; Boyan, B.D. Mechanisms regulating increased production of osteoprotegerin by osteoblasts cultured on microstructured titanium surfaces. Biomaterials 2009, 30, 3390-3396. [CrossRef] [PubMed]

24. Deligianni, D.D.; Katsala, N.; Ladas, S.; Sotiropoulou, D.; Amedee, J.; Missirlis, Y.F. Effect of surface roughness of the titanium alloy Ti-6Al-4V on human bone marrow cell response and on protein adsorption. Biomaterials 2001, 22, 1241-1251. [CrossRef]

25. Guo, J.; Padilla, R.J.; Ambrose, W.; De Kok, I.J.; Cooper, L.F. The effect of hydrofluoric acid treatment of $\mathrm{TiO} 2$ grit blasted titanium implants on adherent osteoblast gene expression in vitro and in vivo. Biomaterials 2007, 28, 5418-5425. [CrossRef]

26. De Oliveira, P.T.; Nanci, A. Nanotexturing of titanium-based surfaces upregulates expression of bone sialoprotein and osteopontin by cultured osteogenic cells. Biomaterials 2004, 25, 403-413. [CrossRef]

27. Scaglione, S.; Guarino, V.; Sandri, M.; Tampieri, A.; Ambrosio, L.; Quarto, R. In vivo lamellar bone formation in fibre coated MgCHA-PCL-composite scaffolds. J. Mater. Sci. Mater Med. 2012, 23, 117-128. [CrossRef]

28. Salmasi, S.; Kalaskar, D.M.; Yoon, W.W.; Blunn, G.W.; Seifalian, A.M. Role of nanotopography in the development of tissue engineered 3D organs and tissues using mesenchymal stem cells. World J. Stem Cells 2015, 7, 266-280. [CrossRef]

29. Lecht, S.; Cohen-Arazi, N.; Cohen, G.; Ettinger, K.; Momic, T.; Kolitz, M.; Naamneh, M.; Katzhendler, J.; Domb, A.J.; Lazarovici, P.; et al. Cytocompatibility of novel extracellular matrix protein analogs of biodegradable polyester polymers derived from alpha-hydroxy amino acids. J. Biomater. Sci. Polym. Ed. 2014, 25, 608-624. [CrossRef]

30. Svanborg, L.M.; Andersson, M.; Wennerberg, A. Surface characterization of commercial oral implants on the nanometer level. J. Biomed. Mater Res. B Appl. Biomater. 2010, 92, 462-469. [CrossRef] 
31. Meirelles, L.; Arvidsson, A.; Albrektsson, T.; Wennerberg, A. Increased bone formation to unstable nano rough titanium implants. Clin. Oral Implants Res. 2007, 18, 326-332. [CrossRef] [PubMed]

32. Meirelles, L.; Melin, L.; Peltola, T.; Kjellin, P.; Kangasniemi, I.; Currie, F.; Andersson, M.; Albrektsson, T.; Wennerberg, A. Effect of hydroxyapatite and titania nanostructures on early in vivo bone response. Clin. Implant. Dent. Relat. Res. 2008, 10, 245-254. [CrossRef]

33. Rajab, F.H.; Liauw, C.M.; Benson, P.S.; Li, L.; Whitehead, K.A. Production of hybrid macro/micro/nano surface structures on Ti6Al4V surfaces by picosecond laser surface texturing and their antifouling characteristics. Colloids Surf. B. Biointerfaces 2017, 160, 688-696. [CrossRef] [PubMed]

34. Yin, C.; Zhang, Y.; Cai, Q.; Li, B.; Yang, H.; Wang, H.; Qi, H.; Zhou, Y.; Meng, W. Effects of the micro-nano surface topography of titanium alloy on the biological responses of osteoblast. J. Biomed. Mater Res. A 2017, 105, 757-769. [CrossRef] [PubMed]

35. Takeuchi, K.; Saruwatari, L.; Nakamura, H.K.; Yang, J.M.; Ogawa, T. Enhanced intrinsic biomechanical properties of osteoblastic mineralized tissue on roughened titanium surface. J. Biomed. Mater. Res. A 2005, 72, 296-305. [CrossRef] [PubMed]

36. Schwartz, Z.; Lohmann, C.H.; Vocke, A.K.; Sylvia, V.L.; Cochran, D.L.; Dean, D.D.; Boyan, B.D. Osteoblast response to titanium surface roughness and 1alpha,25-(OH)(2) $\mathrm{D}(3)$ is mediated through the mitogen-activated protein kinase (MAPK) pathway. J. Biomed. Mater. Res. 2001, 56, 417-426. [CrossRef]

37. Att, W.; Hori, N.; Takeuchi, M.; Ouyang, J.; Yang, Y.; Anpo, M.; Ogawa, T. Time-dependent degradation of titanium osteoconductivity: An implication of biological aging of implant materials. Biomaterials 2009, 30, 5352-5363. [CrossRef]

38. Stein, G.S.; Lian, J.B. Molecular mechanisms mediating proliferation/differentiation interrelationships during progressive development of the osteoblast phenotype. Endocr. Rev. 1993, 14, 424-442. [CrossRef]

39. Siddhanti, S.R.; Quarles, L.D. Molecular to pharmacologic control of osteoblast proliferation and differentiation. J. Cell Biochem. 1994, 55, 310-320. [CrossRef]

40. Alborzi, A.; Mac, K.; Glackin, C.A.; Murray, S.S.; Zernik, J.H. Endochondral and intramembranous fetal bone development: Osteoblastic cell proliferation, and expression of alkaline phosphatase, m-twist, and histone H4. J. Craniofac. Genet. Dev. Biol. 1996, 16, 94-106.

41. Owen, T.A.; Aronow, M.; Shalhoub, V.; Barone, L.M.; Wilming, L.; Tassinari, M.S.; Kennedy, M.B.; Pockwinse, S.; Lian, J.B.; Stein, G.S. Progressive development of the rat osteoblast phenotype in vitro: Reciprocal relationships in expression of genes associated with osteoblast proliferation and differentiation during formation of the bone extracellular matrix. J. Cell Physiol. 1990, 143, 420-430. [CrossRef]

42. Spinella-Jaegle, S.; Roman-Roman, S.; Faucheu, C.; Dunn, F.W.; Kawai, S.; Gallea, S.; Stiot, V.; Blanchet, A.M.; Courtois, B.; Baron, R.; et al. Opposite effects of bone morphogenetic protein-2 and transforming growth factor-beta1 on osteoblast differentiation. Bone 2001, 29, 323-330. [CrossRef]

43. Alliston, T.; Choy, L.; Ducy, P.; Karsenty, G.; Derynck, R. TGF-beta-induced repression of CBFA1 by Smad3 decreases cbfa1 and osteocalcin expression and inhibits osteoblast differentiation. EMBO J. 2001, 20, 2254-2272. [CrossRef] [PubMed]

44. Hori, N.; Iwasa, F.; Ueno, T.; Takeuchi, K.; Tsukimura, N.; Yamada, M.; Hattori, M.; Yamamoto, A.; Ogawa, T. Selective cell affinity of biomimetic micro-nano-hybrid structured $\mathrm{TiO} 2$ overcomes the biological dilemma of osteoblasts. Dent. Mater. 2010, 26, 275-287. [CrossRef] [PubMed]

45. Zhao, G.; Schwartz, Z.; Wieland, M.; Rupp, F.; Geis-Gerstorfer, J.; Cochran, D.L.; Boyan, B.D. High surface energy enhances cell response to titanium substrate microstructure. J. Biomed. Mater. Res. A 2005, 74, 49-58. [CrossRef]

46. Boyan, B.D.; Bonewald, L.F.; Paschalis, E.P.; Lohmann, C.H.; Rosser, J.; Cochran, D.L.; Dean, D.D.; Schwartz, Z.; Boskey, A.L. Osteoblast-mediated mineral deposition in culture is dependent on surface microtopography. Calcif. Tissue Int. 2002, 71, 519-529. [CrossRef]

47. Tsukimura, N.; Yamada, M.; Iwasa, F.; Minamikawa, H.; Att, W.; Ueno, T.; Saruwatari, L.; Aita, H.; Chiou, W.A.; Ogawa, T. Synergistic effects of UV photofunctionalization and micro-nano hybrid topography on the biological properties of titanium. Biomaterials 2011, 32, 4358-4368. [CrossRef]

48. Ogawa, T.; Ozawa, S.; Shih, J.H.; Ryu, K.H.; Sukotjo, C.; Yang, J.M.; Nishimura, I. Biomechanical evaluation of osseous implants having different surface topographies in rats. J. Dent. Res. 2000, 79, 1857-1863. [CrossRef]

49. Ivanovski, S. Osseointegration-the influence of implant surface. Ann. R. Australas Coll Dent. Surg. 2010, 20, $82-85$. 
50. Jaffin, R.A.; Kumar, A.; Berman, C.L. Immediate loading of implants in partially and fully edentulous jaws: A series of 27 case reports. J. Periodontol. 2000, 71, 833-838. [CrossRef]

51. Grassi, S.; Piattelli, A.; Ferrari, D.S.; Figueiredo, L.C.; Feres, M.; Iezzi, G.; Shibli, J.A. Histologic evaluation of human bone integration on machined and sandblasted acid-etched titanium surfaces in type IV bone. J. Oral Implantol. 2007, 33, 8-12. [CrossRef] [PubMed]

52. Grassi, S.; Piattelli, A.; de Figueiredo, L.C.; Feres, M.; de Melo, L.; Iezzi, G.; Alba, R.C., Jr.; Shibli, J.A. Histologic evaluation of early human bone response to different implant surfaces. J. Periodontol. 2006, 77, 1736-1743. [CrossRef] [PubMed]

53. Camarda, A.J.; Milot, P.; Ciaburro, H.; Rompre, P.H.; Sallaleh, I.; Do, C.M.A. Long-term randomized clinical trial evaluating the effects of fixture surface acid-etching and machined collar design on bone healing. Quintessence Int. 2018, 49, 733-743. [CrossRef] [PubMed]

54. Kim, M.H.; Park, K.; Choi, K.H.; Kim, S.H.; Kim, S.E.; Jeong, C.M.; Huh, J.B. Cell adhesion and in vivo osseointegration of sandblasted/acid etched/anodized dental implants. Int. J. Mol. Sci. 2015, 16, 10324-10336. [CrossRef]

55. Weng, D.; Hoffmeyer, M.; Hurzeler, M.B.; Richter, E.J. Osseotite vs. machined surface in poor bone quality. A study in dogs. Clin. Oral Implants Res. 2003, 14, 703-708. [CrossRef]

56. Ogawa, T.; Nishimura, I. Different bone integration profiles of turned and acid-etched implants associated with modulated expression of extracellular matrix genes. Int. J. Oral. Maxillofac. Implants 2003, 18, 200-210.

57. Kubo, K.; Att, W.; Yamada, M.; Ohmi, K.; Tsukimura, N.; Suzuki, T.; Maeda, H.; Ogawa, T. Microtopography of titanium suppresses osteoblastic differentiation but enhances chondroblastic differentiation of rat femoral periosteum-derived cells. J. Biomed. Mater. Res. A 2008, 87, 380-391. [CrossRef]

58. Shim, J.; Nakamura, H.; Ogawa, T.; Gupta, V. An understanding of the mechanism that promotes adhesion between roughened titanium implants and mineralized tissue. J. Biomech. Eng. 2009, 131, 054503. [CrossRef]

59. Hori, N.; Ueno, T.; Suzuki, T.; Yamada, M.; Att, W.; Okada, S.; Ohno, A.; Aita, H.; Kimoto, K.; Ogawa, T. Ultraviolet light treatment for the restoration of age-related degradation of titanium bioactivity. Int. J. Oral Maxillofac. Implants 2010, 25, 49-62.

60. Att, W.; Hori, N.; Iwasa, F.; Yamada, M.; Ueno, T.; Ogawa, T. The effect of UV-photofunctionalization on the time-related bioactivity of titanium and chromium-cobalt alloys. Biomaterials 2009, 30, 4268-4276. [CrossRef]

61. Saruwatari, L.; Aita, H.; Butz, F.; Nakamura, H.K.; Ouyang, J.; Yang, Y.; Chiou, W.A.; Ogawa, T. Osteoblasts generate harder, stiffer, and more delamination-resistant mineralized tissue on titanium than on polystyrene, associated with distinct tissue micro- and ultrastructure. J. Bone Miner. Res. 2005, 20, 2002-2016. [CrossRef] [PubMed]

62. Kim, R.H.; Williams, D.W.; Bae, S.; Lee, R.S.; Oh, J.E.; Mehrazarin, S.; Kim, T.; Shin, K.H.; Park, N.H.; Kang, M.K. Camphorquinone inhibits odontogenic differentiation of dental pulp cells and triggers release of inflammatory cytokines. J. Endod 2013, 39, 57-61. [CrossRef] [PubMed]

63. Saruta, J.; To, M.; Sugimoto, M.; Yamamoto, Y.; Shimizu, T.; Nakagawa, Y.; Inoue, H.; Saito, I.; Tsukinoki, K. Salivary Gland Derived BDNF Overexpression in Mice Exerts an Anxiolytic Effect. Int. J. Mol. Sci. 2017, 18, 1902. [CrossRef] [PubMed]

64. Ozawa, S.; Ogawa, T.; Iida, K.; Sukotjo, C.; Hasegawa, H.; Nishimura, R.D.; Nishimura, I. Ovariectomy hinders the early stage of bone-implant integration: Histomorphometric, biomechanical, and molecular analyses. Bone 2002, 30, 137-143. [CrossRef]

(C) 2020 by the authors. Licensee MDPI, Basel, Switzerland. This article is an open access article distributed under the terms and conditions of the Creative Commons Attribution (CC BY) license (http://creativecommons.org/licenses/by/4.0/). 